\title{
LA DIRECTIVA DE RETORNO Y LA TUTELA JUDICIAL EFECTIVA
}

\author{
RETURN DIRECTIVE AND EFFECTIVE JUDICIAL PROTECTION
}

\author{
Isabel Reig Fabado \\ Universidad de Valencia. España/Spain \\ isabel.reig@uv.es
}

Recibido/Received: 22/01/2015

Aceptado/Accepted: 29/04/2015

\section{RESUMEN}

Después de cierto tiempo de aplicación, la Directiva de Retorno 2008/115 contiene elementos que suscitan un especial interés por afectar a los derechos procesales fundamentales de los extranjeros nacionales de terceros Estados en situación de retorno. Pero, además, su proyección afecta a la configuración de una nueva política migratoria de la Unión Europea que supone sin temor a la exageración el verdadero reto para el siglo XXI. Una política que debe respetar los derechos básicos de los extranjeros y permitir la integración en un espacio de libertad, justicia y seguridad. El presente trabajo señala luces y sombras en el camino desarrollado por la Directiva de retorno, su transposición por los Derechos estatales, la aplicación de la misma y la jurisprudencia del TJUE en su interpretación precisamente en el momento en que se plantea su modificación.

\section{PALABRAS CLAVE}

Retorno, nacionales de terceros Estados, derechos procesales fundamentales.

\section{SUMARIO}

I. Introducción. II. La Directiva 2008/115/Ce de Retorno. II.1. Tutela judicial efectiva: garantías procesales y asistencia jurídica gratuita. II.1.a. Garantías procesales en la Directiva de Retorno. II.1.b. La asistencia jurídica gratuita en la Directiva de Retorno. II.2. Internamiento a efectos de expulsión. III. La jurisprudencia del TJUE y la Directiva de Retorno. IV. Conclusiones. Bibliografía.

\begin{abstract}
After a certain time of application, the Return Directive 2008/115 contains elements that give rise to a special interest which affect the fundamental procedural rights of foreign nationals of third countries in return situation. But also, its projection affects the configuration of a new immigration policy of the European Union which is without fear of exaggeration, the real challenge for the XXI century. A policy that must respect the basic rights of foreigners and allow integration into an area of freedom, security, and justice. This paper points out lights and shadows on the path developed by the Return Directive on its transposition by European members, the application thereof and the jurisprudence of the ECJ in its interpretation precisely at the moment amendment arises.
\end{abstract}

\section{KEYWORDS}

Return nationals of third countries, fundamental procedural rights.

\section{CONTENTS}

I. Introduction. II. Return Directive 2008/115/EC. II.1. Effective judicial protection: process and legal aid. II.1.a. Process in the Return Directive. II.1.b. Legal aid in the Return Directive . II.2. Internment for expulsion purposes. III. ECJ Jurisprudente and Return Directive. IV. Conclusions. References. 


\section{INTRODUCCIÓN}

Uno de los retos más importantes para la Unión Europea en la actualidad consiste en articular una política migratoria europea integral que sea valedora de los principios comunitarios fundacionales. Hasta la fecha, la política migratoria europea ha supuesto una suerte de defensa externa basada en la creación del espacio Schengen para garantizar el control único y la seguridad intra-comunitaria. En este contexto se han elaborado una serie de medidas continuistas en esta línea y, asimismo, restrictivas o limitadoras de derechos.

Así, esta involución encuentra uno de sus mejores exponentes en la Directiva 115/2008 relativa a normas y procedimientos comunes en los Estados miembros para el retorno de los nacionales de terceros países en situación irregular que es conocida, de forma generalizada, como la "Directiva de Retorno". En esta Directiva se establecen medidas comunes para los Estados de la Unión Europea (aunque no se incluyen todos) relativas al procedimiento de retorno de nacionales de terceros países que consta de dos fases: el retorno voluntario y el forzoso.

En marzo de 2014 la Comisión ha presentado el informe, previsiblemente optimista, sobre la aplicación de la Directiva de Retorno bajo el título: "Comunicación al Consejo y al Parlamento Europeo sobre la política de retorno de la UE" (2014). Además cabe señalar, entre otros, la existencia de otro informe coetáneo en sentido opuesto -elaborado por ONGs y bajo el auspicio de la Comisión Europea- que es el Informe Ad the Limen: the implementation of the return Directive in Cyprus, Italy and Spain (2013).

Los principios básicos que inspiraban el origen de esta normativa resultaban en línea con la tradición garantista que venía desarrollando la actual Unión Europea desde sus inicios. Sin embargo, ciertos elementos restrictivos en los derechos fundamentales de los extranjeros que se introdujeron en esta normativa exigen una vuelta a esta tradición jurídica europea en la defensa de los derechos civiles y a la consecución de un verdadero espacio europeo de libertad, seguridad y justicia (Rubio y Moya, 2011:22). Ello se concreta en la introducción de recortes en los derechos de los inmigrantes en situación irregular que se manifiestan en medidas como la prohibición de readmisión, la posibilidad de retención en centros de internamiento hasta un plazo máximo de 18 meses o la falta de garantías jurídicas en especial -aunque no solo- para con los colectivos vulnerables, como por ejemplo los menores. En el caso español, la transposición de la Directiva de Retorno en 2009 a través de la Ley Orgánica 2/2009, suscitó modificaciones de la normativa española de extranjería (la Ley Orgánica 4/2000, de 11 de enero, sobre derechos y libertades de los extranjeros en España y su integración social, con todas las modificaciones experimentadas, así como al Real Decreto 557/2011, de 20 de abril, por el que se aprueba el Reglamento de la Ley Orgánica 4/2000, sobre derechos y libertades de los extranjeros en España y su integración social). Transposición polémica debido al aumento del plazo máximo de internamiento de los extranjeros de 40 a 60 días (Pérez, 2012:4).

Esta Directiva se erige con el objetivo de alcanzar la consecución de un espacio de libertad, seguridad y justicia (Iglesias, 2006:8). Los Consejos Europeos de Tampere -en 1999- y de Salónica -en 2003- han ido configurando y consolidando los principios sobre los que debe inspirarse el desarrollo de las políticas comunitarias en materia de migración y retorno. Asimismo, el Consejo Europeo de Bruselas - de 2004- estableció, una doble necesidad en la política de retorno: la de erigir normas que sean comunes y que respeten los derechos humanos.

En este sentido, debe tenerse en cuenta la jurisprudencia del Tribunal Constitucional español que ha sido tajante en la defensa de los derechos fundamentales de los extranjeros en 
España - considerando, en este punto, como irrelevante la consideración administrativa de regularidad o no-, que no ha dudado en declarar la inconstitucionalidad de algunos preceptos de la Ley Orgánica de Extranjería, y de otros textos, que pretendían limitar el ejercicio de alguno de estos derechos (Sentencias del TC, de 7 de julio de 1987, núm. 115/1987 y de 7 de noviembre de 2007).

En consecuencia, este amplio margen de discrecionalidad para los Estados miembros puede acabar constituyendo un obstáculo para la armonización, es decir, para la consecución de un conjunto de normas comunes. Ello se explica porque la Directiva pretendía establecer un estándar mínimo para los entonces 27 Estados miembros de la UE que elevara los niveles de regulación de países miembros con un grado de desarrollo legislativo menor.

\section{LA DIRECTIVA 2008/115/CE DE RETORNO}

\section{II.1. La tutela judicial efectiva: garantías procesales y asistencia jurídica gratuita}

Las garantías procesales suponen la expresión de un derecho fundamental de toda persona, reconocido en el artículo 24 de la CE de 1978: el derecho a la tutela judicial efectiva, así como su proyección en el beneficio de justicia gratuita para todas las personas que acrediten insuficiencia de medios económicos para litigar (art. 119 CE). La legislación española de extranjería acoge este mandato constitucional (incluido también en tratados internacionales) por cuanto que no sólo reconoce estos derechos fundamentales procesales sino que, además, establece una serie de garantías para su salvaguarda. De suerte que la Ley Orgánica 4/2000, en su Capítulo III (arts. 20 a 22), regula el derecho a la tutela judicial efectiva y el derecho a la asistencia jurídica gratuita mediante el establecimiento de una serie de medidas para garantizar su ejercicio (Esplugues, 2011:53).

Bajo este contexto, el planteamiento por el que ha optado la Directiva de Retorno con respecto a las garantías procedimentales, presenta ciertos elementos restrictivos por comparación o, incluso, podría afirmarse sin ambages, que resulta menos garantista. De un lado, por lo que respecta a la tutela judicial efectiva, conviene realizar algunas precisiones en la materia objeto de comentario. En primer lugar, la tutela judicial efectiva tiene como objetivo básico evitar la indefensión y se reconoce a toda persona por el hecho de serlo, con independencia de su condición de nacional o extranjero y, en este último supuesto, resultando irrelevante su situación administrativa de regular o irregular. Asimismo, el derecho a la tutela judicial efectiva presenta dos dimensiones, la formal, en primer lugar, y la material, en segundo. El sentido formal de este derecho se concreta en el libre acceso a los jueces y tribunales; mientras que su sentido material se concreta en la obtención de una decisión judicial sobre el fondo del asunto y su ejecución. Además, este derecho se proyecta en una serie de garantías como, entre otras, el derecho a un juez imparcial e independiente (Sentencias del Tribunal Europeo de Derechos Humanos, de 22.04.2004 en el asunto Cianetti; y de 07.06.2005, en el asunto Chmelír) predeterminado por la Ley y a un juicio justo, asistencia letrada, información y motivación debidas (Sentencias del Tribunal Europeo de Derechos Humanos de 02.06.2005, de 18.04.2006 y de 16.01.2007), medios de prueba para la defensa, garantías procedimentales de notificación y emplazamiento, derecho a un recurso jurisdiccional efectivo o la presunción de inocencia (Sentencia del Tribunal Europeo de Derechos Humanos de 21.12.2006, en el asunto Borisova). De esta manera, los inmigrantes en situación irregular que se encuentren en España inmersos en un proceso de retorno gozan de todas las garantías derivadas del derecho a la tutela judicial efectiva. Esta 
consideración ha sido refrendada por el Tribunal Constitucional español. Así, la jurisprudencia constitucional ha reconocido el derecho a la tutela judicial efectiva como un derecho fundamental procesal que ostenta toda persona sin ninguna discriminación por razón de nacionalidad. Asimismo, el Tribunal Constitucional español también se ha decantado por una interpretación extensiva en la que, junto al derecho fundamental de libre acceso a los tribunales, deben incluirse todas las garantías ya citadas, "sin posibilidad de restricción alguna" (Sentencias del Tribunal Constitucional de 23.05.1985; de 30.09.1985; de 07.07. 1987; de 25.11.1997; de 22.05.2003; de 7.11.2007; y de 9.6.2011).

Sin embargo, del análisis de las garantías formales, de recurso y respecto de la situación de espera del retorno que desarrolla el Capítulo III de la Directiva y que se han comentado anteriormente, podría derivarse un tratamiento restrictivo de este derecho fundamental. Ello se debe a que se plantean algunas cuestiones que podían colisionar con la realización efectiva del derecho a la tutela judicial efectiva: específicamente, determinadas limitaciones de garantías procesales básicas, como la obligación de información y motivación, así como la obligación de traducción (Sentencia del Tribunal de Justicia de 08.11.2005, en el asunto Leffler). En concreto, la posibilidad de limitar la información a la persona afectada sobre los fundamentos de hecho del artículo 12 -según la legislación nacional y al amparo de motivos de seguridad nacional- podría perturbar la obligación de motivación debida de dichas decisiones y de las vías de recurso situando, incluso, a la persona implicada en una situación de posible indefensión. En el mismo sentido, podría denunciarse el "carácter facultativo" de la obligación de traducción de las decisiones de retorno y la vía de recurso cuando se trata de personas que han entrado de manera ilegal y no obtienen autorización para su permanencia en ese Estado. Obviamente, la posible ausencia de información y/o traducción tampoco parece que pueda garantizar la plena eficacia del derecho de defensa (Pardo, 2009), ni siquiera por lo que respecta a las vías de recurso para las que tampoco se determina definitivamente la vía jurisdiccional. Todo ello lleva a plantear, para determinadas situaciones, serias dudas sobre el ejercicio de la tutela judicial efectiva, sobre todo en relación con un colectivo de inmigrantes -los que se encuentran en situación irregular- especialmente vulnerable a la indefensión que deberían poder ejercitarlo, como se ha visto, en las mismas condiciones y con la misma legitimidad que el resto de personas -extranjeros y nacionales-.

\section{II.1.a. Garantías procesales en la Directiva de Retorno}

En el análisis del contenido de la Directiva de Retorno, el Capítulo III -artículos 12 a 14-, bajo la misma rúbrica, contiene el desarrollo de las "garantías procedimentales" que deben acompañar a las medidas de retorno. Precisamente, este Capítulo de la Directiva de Retorno se titula "Garantías procedimentales". En él se incluyen tres tipos de garantías diferentes. Por lo que se refiere a la forma, las decisiones de retorno, de prohibición de entrada y de expulsión se dictarán por escrito, serán motivadas (fundamentos de hecho y de derecho), y contendrán información sobre las vías de recurso existentes. No obstante, la información sobre los fundamentos de hecho podrá limitarse, de conformidad con el Derecho nacional, para salvaguardar la seguridad nacional, la defensa, la seguridad pública y para la prevención, investigación, detección y persecución de delitos. A instancia de parte, los Estados miembros proporcionarán una traducción de las decisiones de retorno y las vías de recurso disponibles, en una lengua que el nacional de un tercer país comprenda o pueda suponerse razonablemente que comprende. No obstante, esta obligación es facultativa en el caso de nacionales de terceros países que hayan entrado ilegalmente en el territorio de un Estado miembro y que no hayan obtenido ulteriormente una autorización o derecho de 
estancia en él. En tales casos, las decisiones de retorno se notificarán a través de un formulario normalizado según disponga la legislación nacional (art. 12).

En segundo lugar, la Directiva de Retorno establece el derecho a un recurso jurisdiccional efectivo contra las decisiones relativas al retorno o pidiendo que se revisen éstas ante un órgano jurisdiccional, una autoridad administrativa $u$ otro órgano competente compuesto por miembros imparciales y con garantías de independencia, pudiendo asimismo suspender temporalmente su ejecución (art. 13). El nacional de un tercer país tendrá la posibilidad de obtener asesoramiento jurídico, representación y, en su caso, asistencia lingüística. La asistencia jurídica y/o la representación legal necesaria se concederá, previa solicitud, de forma gratuita con arreglo a la legislación nacional o, si así lo decide el Estado miembro, en las condiciones establecidas en el artículo 15, apartados 3 a 6, de la Directiva 2005/85/CE del Consejo, de 1 de diciembre de 2005, sobre normas mínimas para los procedimientos que deben aplicar los Estados miembros para conceder o retirar la condición de refugiado.

Finalmente, la Directiva de Retorno establece una serie de garantías a la espera del retorno. Con la salvedad de lo que se dispone en los casos de internamiento a efectos de expulsión, durante el plazo para la salida voluntaria concedido de conformidad con el artículo 7 y durante los períodos de aplazamiento de la expulsión de conformidad con el artículo 9, los Estados miembros velarán, "en la medida de lo posible", porque se tengan en cuenta los siguientes principios en relación con los nacionales de terceros países: a) mantenimiento de la unidad familiar con los miembros de la familia presentes en su territorio; b) prestación de atención sanitaria de urgencia y tratamiento básico de enfermedades; c) acceso para los menores, en función de la duración de su estancia, al sistema de enseñanza básica; y d) consideración hacia las necesidades especiales de las personas vulnerables. Además, debe proporcionarse a estas personas confirmación escrita, de conformidad con la legislación nacional, de que se ha prorrogado el plazo para su salida voluntaria o de que la ejecución de la decisión de retorno se suspenderá temporalmente (art. 14).

\section{II.1.b. La asistencia jurídica gratuita en la Directiva de Retorno}

Otra cuestión que se manifiesta como extensión del derecho a la tutela judicial efectiva es el derecho a la asistencia jurídica gratuita (art. 119 CE y diversos textos internacionales y europeos). En este sentido, la jurisprudencia del Tribunal Constitucional español ha reiterado su posición, en línea con lo sostenido anteriormente, de reconocer este derecho -siempre y cuando se acrediten la falta de recursos económicos para litigar- como extensión del primero y como derecho que asiste a toda persona sin poder realizar ningún tipo de discriminación. Y ello específicamente en relación con la tendencia legislativa existente al recorte del reconocimiento de este derecho a los extranjeros que se encuentran en situación irregular. De este modo, el beneficio de justicia gratuita debe reconocerse a nacionales y extranjeros y, entre estos últimos, con independencia del carácter regular o no de su situación. En este sentido, y por esta razón, el Tribunal Constitucional español, en diferentes ocasiones, no ha dudado en declarar la inconstitucionalidad de diversos preceptos, tanto de la Ley 1/1996, de 10 de enero, de asistencia jurídica gratuita, modificada por la Ley 16/2005, de 18 de julio, como de la Ley Orgánica 4/2000 de Extranjería. En ambos textos se pretendía limitar el ejercicio del derecho de asistencia jurídica gratuita a los extranjeros en situación irregular y, para los dos casos y en distintas ocasiones, el Tribunal Constitucional declaró la inconstitucionalidad de los preceptos que pretendían restringir el beneficio de justicia gratuita únicamente para los extranjeros en situación "regular" (Sentencias del Tribunal Constitucional de 22.05.2003, de 07.11.2007 y de 11.11.2007). La normativa española de 
extranjería viene a solventar la adaptación constitucional -mediante la Ley 2/2009- por cuanto que reconoce el derecho a la asistencia jurídica gratuita a los extranjeros que "se hallen" en España -sin distinciones-, para todos los órdenes jurisdiccionales y en igualdad de condiciones con los españoles. Garantiza, además, las condiciones de su ejercicio en los procedimientos administrativos de retorno y asilo, mediante el reconocimiento del derecho a la interpretación, a la gratuidad en vía de recurso.

Lo cierto es que, por comparación, la referencia al beneficio de justicia gratuita en la Directiva de Retorno resulta en cierto grado inquietante, por cuanto tampoco parece garantizarse el ejercicio efectivo del mismo. Ello es así por cuanto el artículo 13.4 de la Directiva de Retorno transfiere el control del cumplimiento de dicho ejercicio a los Estados miembros bajo la genérica fórmula "los Estados miembros velarán..." por la asistencia jurídica gratuita. En la misma línea de "recomendación" establece que aquéllos "podrán" remitirse a la Directiva 2005/85/CE.

El problema es que si se ejerce esta posibilidad -la de remisión a la citada Directiva 115/2008- el artículo 15, párrafos 3, 4 y 5 lo que se obtiene, fundamentalmente, es una enumeración de limitaciones de este derecho procesal fundamental. De suerte que este precepto establece: “3. Los Estados miembros podrán establecer en su Derecho nacional que se conceda asistencia jurídica o representación legal gratuitas: a.- únicamente para los procedimientos ante un órgano jurisdiccional de conformidad con el Capítulo $\mathrm{V}$ y no para nuevos recursos o revisiones previstos en el Derecho nacional, incluida la revisión de un recurso debida a un nuevo recurso o revisión, y o b.- únicamente a quienes carezcan de medios suficientes, y o c.- únicamente a los asesores jurídicos u otros consejeros designados específicamente por el Derecho nacional para asistir o representar a los solicitantes de asilo, y o d.- únicamente si el recurso o revisión tiene probabilidades de prosperar. Los Estados miembros velarán por que no se restrinja de manera arbitraria la asistencia jurídica ni la representación legal concedidas en virtud de la letra d. 4. Los Estados miembros podrán establecer normas para dar respuesta y tratar tales peticiones de asistencia jurídica o representación legal. 5. Los Estados miembros podrán además: a.- imponer límites económicos y o temporales a la disposición relativa a la asistencia jurídica y o representación legal gratuita, siempre que dichos límites no restrinjan de manera arbitraria el acceso a la asistencia jurídica y o representación legal; b.- disponer que, por lo que respecta a las tasas y otros gastos, el trato a los solicitantes no sea más favorable que el que generalmente conceden a sus nacionales en asuntos de asistencia jurídica. 6. Los Estados miembros podrán exigir el reembolso total o parcial de cualquier gasto sufragado cuando la situación financiera del solicitante haya mejorado considerablemente o si la decisión de conceder tales beneficios se hubiese adoptado sobre la base de información falsa suministrada por el solicitante" (la cursiva es nuestra).

En este contexto, las características de la remisión, sin carácter obligatorio, resultan correlativas a la aproximación más bien limitativa al beneficio de justicia gratuita, que es manifestación de la tutela judicial efectiva. En cualquier caso, y en relación con las citadas "limitaciones" y "vaguedades" en torno a la tutela judicial efectiva, resulta una situación paradójica si se incide en la referencia que se hace a la misma al inicio de la Directiva de Retorno, concretamente en su Considerando 11. De suerte que, en lo que podría calificarse como la "Exposición de motivos" del texto, la referencia es clara y taxativa: "Debe establecerse un conjunto mínimo común de garantías jurídicas respecto de las decisiones relativas al retorno para garantizar una protección eficaz de los intereses de las personas de que se trate. Debe facilitarse la asistencia jurídica necesaria a aquellas personas que no 
dispongan de recursos suficientes. Los Estados miembros deben prever en su legislación nacional los casos en que considera necesaria la asistencia jurídica" (la cursiva es nuestra).

\section{II.2. Internamiento a efectos de expulsión}

El Capítulo IV de la Directiva de Retorno, titulado "Internamiento a efectos de expulsión" suscita importantes dudas acerca de su compatibilidad con la protección de los derechos fundamentales, tanto por lo que en este Capítulo se omite, como por sus disposiciones expresas (Barreiro, 2013: 9).

En la Directiva de Retorno se echa en falta una referencia a que deben estar prohibidas tanto las decisiones de retorno como las órdenes de expulsión que tengan carácter colectivo. El silencio de la Directiva de Retorno sobre este particular no puede interpretarse en el sentido de que permita a los Estados miembros apartarse de esta prohibición, aunque la opción legislativa seguida, consistente en guardar silencio sobre este particular, no haya sido la más correcta.

Otra omisión importante en la Directiva de Retorno relativa a la protección de derechos concierne al derecho a reparación en caso de internamiento ilegal. Es cierto que la Directiva de Retorno, cuando quien dicta el internamiento es una autoridad administrativa, establece la posibilidad de un control judicial a posteriori, ya sea de oficio o a instancia de parte. Si como resultado del ejercicio del mismo, se considera que el internamiento es ilegal, la Directiva establece la obligación de poner inmediatamente en libertad a la persona de que se trate (art. 15.2, pár. 4), si bien se guarda un discreto silencio sobre el derecho de esta persona a resarcimiento.

De la regulación específica del Capítulo IV de la Directiva de Retorno plantean serios problemas las disposiciones relativas a las autoridades que pueden ordenar el internamiento a efectos de expulsión, su duración y las condiciones del mismo. Cabe recordar que el artículo 15.2 de la Directiva de Retorno expresamente señala que "el internamiento será ordenado por las autoridades administrativas o judiciales". Los problemas se plantean cuando sean autoridades no judiciales quienes ordenen el internamiento. Por lo que se refiere al Derecho español, este tema ya fue resuelto por el Tribunal Constitucional en su Sentencia 115/1987, de 7 de julio. Por lo tanto, el Tribunal Constitucional español dejó claro que la detención preventiva ordenada por una autoridad administrativa española no puede exceder de las 72 horas, plazo en el que el detenido deberá quedar en libertad o ser puesto a disposición judicial (art. 17.2 CE). El Tribunal Constitucional concluyó afirmando que: "La voluntad de la ley, y desde luego el mandato de la Constitución es que, más allá de las setenta y dos horas, corresponda a un órgano judicial la decisión sobre mantenimiento o no de la limitación de la libertad". En consecuencia, la previsión de la Directiva de Retorno de que una autoridad administrativa pueda dictar una orden de internamiento por un plazo máximo de seis meses (art. 15.5), prorrogable por esa misma autoridad administrativa por un plazo no superior a doce meses más (art. 15.6) choca directamente con el mandato constitucional y cualquier medida española de incorporación de esta Directiva que la siguiera incurriría necesariamente en un vicio de inconstitucionalidad. Asimismo, las detenciones prolongadas ordenadas por autoridades administrativas, que en ningún caso tienen la consideración de órganos judiciales, aunque permitida por la Directiva de Retorno, sería igualmente contraria al Convenio europeo para la protección de los derechos humanos y de las libertades fundamentales.

Plantea igualmente dudas de compatibilidad con la protección de derechos fundamentales, y por lo tanto de constitucionalidad, las disposiciones de la Directiva de Retorno relativas a la 
información que se debe dar a los naciones de terceros países en situación irregular en relación con la eventual existencia de un recurso judicial a instancia de parte para controlar la legalidad de la orden administrativa de internamiento. El artículo 15.2 párrafo 3, b) de la Directiva de Retorno afirma que: "En este caso, los Estados miembros informarán inmediatamente al nacional de un tercer país de que se trate sobre la posibilidad de incoar dicho procedimiento". Ninguna referencia se contiene acerca de que esta información se le deba dar en un idioma que comprenda. De nuevo cabe referirse al Convenio europeo para la protección de los derechos humanos y de las libertades fundamentales, que en su artículo 5.2 dispone que: "Toda persona detenida preventivamente debe ser informada, en el más breve plazo y en una lengua que comprenda, de los motivos de su detención y de cualquier acusación formulada contra ella". De no cumplirse esta garantía mínima, se estaría atentando contra los derechos de defensa judicial de la persona afectada, deviniendo por tanto inconstitucional cualquier práctica de este tipo.

Asimismo, otra cuestión que suscita serias dudas es la referida a la regulación que la Directiva de Retorno hace de la duración del internamiento a efectos de expulsión. La Directiva en este punto resulta contradictoria, pues a la afirmación de que "cualquier internamiento será lo más corto posible" (art. 15.1, pár. 2), le sigue la posibilidad de que el internamiento pueda prolongarse hasta 18 meses (art. 15.5 y 6). Cabe recordar que, cuando el Tribunal Constitucional español declaró la constitucionalidad del artículo 26.2, párrafo segundo, de la Ley Orgánica 7/1985, sobre derechos y libertades de los extranjeros en España, lo hizo atendiendo a que el plazo de internamiento de 40 días -y no los 60 días de la actual normativa española- coincide con "la duración máxima de la prisión preventiva de los extranjeros prevista en el artículo 16.4 del Convenio Europeo de Extradición”. En consecuencia, los plazos previstos en la Directiva de Retorno chocan con este canon de constitucionalidad. Debe señalarse, además, que la Directiva de Retorno guarda un más que discreto silencio ante la eventualidad de que, una vez transcurridos los 18 meses de internamiento, siga sin haberse producido la expulsión. En estos casos, debería procederse a la liberación inmediata de la persona afectada. No obstante, surge la duda de si, a continuación, se le podría dictar una nueva orden de internamiento que lleve al cómputo del plazo de 18 meses (Sentencias del TJUE de 30.11.2009, C-357/09, en el asunto Kadzoev, y en los asuntos acumulados de 30.4.2014, C473/13, el asunto Bero, C 515/13 en el asunto Bouzalmate y C474/13, en el asunto Ly Pham).

Finalmente, debe señalarse que también se plantean problemas en las condiciones de internamiento previstas en la Directiva de Retorno. Cabe recordar que la Directiva de Retorno establece, como norma general, que el internamiento se lleve a cabo en centros de internamiento especializados, aunque cuando un Estado miembro no pueda llevar a cabo esta previsión, podrá recurrir a centros penitenciarios, donde las personas en situación irregular internadas estarán separadas de los presos ordinarios (art. 16.1). No obstante, en situaciones en que un número excepcionalmente importante de personas en situación irregular que deban ser retornadas plantee una "importante carga imprevista" para la capacidad de las instalaciones de internamiento de un Estado miembro, no será necesario cumplir lo dispuesto en su artículo 16.1 (art. 18.1). De nuevo, cabe recordar que esta regulación atenta contra la jurisprudencia constitucional española, pues al declarar la constitucionalidad del artículo 26.2, párrafo segundo, de la Ley Orgánica 7/1985, sobre derechos y libertades de los extranjeros en España, el Tribunal Constitucional tuvo en cuenta que: “(...) el internamiento ha de ser en centros o locales "que no tengan carácter penitenciario", garantía adicional que trata de evitar que el extranjero sea sometido al tratamiento propio de los centros penitenciarios", cuando su situación es de carácter administrativo. 


\section{LA JURISPRUDENCIA DEL TJUE Y LA DIRECTIVA DE RETORNO}

Tras sus correspondientes transposiciones y después de cierto tiempo en su aplicación, lo cierto es que la práctica ha instalado algunos elementos comunes que han requerido la intervención del Tribunal de Justicia de la Unión Europea (en adelante TJUE). Tal y como ha acontecido con la injerencia de la normativa penal de los Estados miembros de la Unión Europea en las situaciones de retorno de nacionales de terceros Estados y la desigual aplicación de la política de retorno en los diferentes Estados de la Unión Europea que lleva a plantear su próxima modificación. De modo que, el objeto de este trabajo se centra en algunos derechos fundamentales, como ocurre en la adopción de medidas relativas a la tutela judicial efectiva, los plazos de internamiento o la protección de menores. Asimismo, conviene referenciar la aplicación de la Directiva por los Estados, así como la jurisprudencia del TJUE que, desde la existencia de la Directiva de Retorno, ha perfilado algunos aspectos interpretativos en relación, sobre todo, con la incompatibilidad de las medidas de Derecho penal de los Estados miembros en relación con las situaciones de retorno de nacionales de terceros Estados en situación administrativa irregular (Lancha, 2014:214).

Ciertamente, el desarrollo de la práctica en la jurisprudencia del TJUE ha centrado el problema en la injerencia de las normas de Derecho penal estatales (por ejemplo, Italia) en las situaciones de retorno de nacionales de terceros Estados reguladas por la propia Directiva (Iglesias, 2009:23).

Estas circunstancias plantean el problema de la compatibilidad de las normas penales de los Derechos estatales de los Estados miembros con la Directiva de retorno que, además, viene siendo tratado por la jurisprudencia del TJUE (Sorroza, 2008:34). En efecto, si bien la Directiva de Retorno no pierde margen en su ámbito de aplicación para las situaciones de retorno, lo cierto es que los Estados miembros siguen conservando su competencia en materia penal para el establecimiento de sanciones penales en las situaciones de retorno o, en otras palabras, la criminalización de la inmigración irregular, por ejemplo en países como Francia o Italia (Parrot, 2011:345; Poissonnier, 2011:124).

Con carácter general, el TJUE ha optado por establecer la incompatibilidad de las normas penales estatales con la Directiva de retorno cuando aplican una pena privativa de libertad criminalizando per se la inmigración irregular en una situación de retorno (Sentencia del TJUE, de 28.4.2011, C-61/11, en el asunto El Dridi, la Sentencia del TJUE de 30.11.2009, C-357/09, en el asunto Kadzoev, y González Saquero, 2011: 323). Sin embargo, el Tribunal europeo matiza esta afirmación de forma casuística declarando, en algún caso, la compatibilidad con este tipo de penas -de encarcelamiento- cuando se ha aplicado el procedimiento de retorno, si el plazo máximo de internamiento ha expirado y no existe causa que justifique el no retorno (Sentencias del TJUE, de 6.12.2011, C-329/11, en el asunto Achughbabian y de 3.7.2014, C-189/13, en el asunto Da Silva); y, en otros, declarando la compatibilidad de los sistemas mixtos/sustitutivos multa/expulsión con la Directiva de Retorno y la incompatibilidad con el arresto domiciliario cuando éste obstaculiza el retorno (Sentencia del TJUE, de 6.12.2012, C-430/11, en el asunto Sagor y Auto del TJUE de 21.3.2013, C-357/09, en el asunto Mbaye). Asimismo, el TJUE declara tajantemente la obligación de separar a los internos por retorno de los presos comunes, como garantía de los derechos de los extranjeros, lo que sensu contrario implica la permisibilidad con respecto al internamiento en centro penitenciarios ante la ausencia de centros especializados, como es el caso de Alemania (Sentencia del TJUE de 17.7.2014, en los asuntos acumulados: C-473/13, en el asunto Bero, C-514/13, en el asunto Bouzalmate y C-474/13 en el asunto Ly Pham. 
Asimismo, en relación con las prohibiciones de entrada -anteriores y posteriores a la entrada en vigor de la Directiva de retorno- Sentencia del TJUE, de 19.9.2013, C-297/12, en el asunto Osmani).

Con respecto a derechos procesales fundamentales como la contradicción y audiencia, el TJUE también se pronuncia en algunas de sus decisiones si bien de forma ambivalente. Así, el Tribunal afirma que los derechos de defensa deben ser respetados si bien no siempre su infracción conduce a la anulación de la resolución (Sentencia del TJUE de 10.9.2013, C383/13, en el asunto PPU; Sentencia del TJUE de 5.11.2014, C-166/13, en el asunto Mukarubega y Sentencia del TJUE de 11.12.2014, C-249/13, en el asunto Boudjilida).

Otra de las cuestiones abordadas por la jurisprudencia del TJUE afecta a las relaciones entre el régimen jurídico del retorno de nacionales de terceros Estados y la protección en materia de asilo. Concretamente, referido a la situación en la que un extranjero internado realice la solicitud de asilo posponiendo, de este modo, el retorno. En este caso, el Tribunal europeo afirma la posibilidad de mantener la situación de internamiento en aplicación de la normativa protectora de asilo, sin que resulten necesariamente situaciones contradictorias (Sentencia del TJUE, de 30.5.2013, C-534/11, en el asunto Arslan. Asimismo, sobre atención sanitaria básica y de urgencia en relación con el estatuto de refugiado y la protección subsidiaria vid., la Sentencia del TJUE de 18.12.2014, C-562/13, en el asunto Abdida).

El TJUE se afana, pues, en practicar un difícil equilibrismo entre la compatibilidad de la Directiva de Retorno con los Derechos estatales y la garantía de los derechos procesales básicos de los nacionales de terceros Estados en situación de retorno, incluso cuando son vulnerados.

\section{CONCLUSIONES}

La Directiva de Retorno resulta especialmente controvertida para los Estados miembros que ya tienen una legislación desarrollada en materia de retorno de extranjeros. Y ello porque la armonización a la que conduce el establecimiento de procedimientos y normas comunes en esta materia se ha realizado, a todas luces, estableciendo un "estándar mínimo" de protección de los derechos fundamentales procesales de los extranjeros que no siempre alcanza los niveles básicos requeridos. Circunstancia que ha permitido a algunos países como Italia, Alemania o Francia dar una vuelta de tuerca a la política migratoria bajo la criminalización de la inmigración irregular. El caso español no plantea mayores problemas en la transposición de la Directiva, si bien se ha incidido en determinados aspectos de la Directiva de Retorno que presentan ciertas deficiencias. Tal y como se ha señalado en relación con las garantías procesales relativas a la tutela judicial efectiva o el internamiento a efectos de expulsión.

La propia Directiva sostiene que la Directiva debe proporcionar un valor añadido europeo (Considerando 19). Precisamente y, sin embargo, la aplicación de la Directiva de Retorno se ha realizado de forma irregular por los diferentes Estados y con ciertas dudas sobre su eficacia hasta el punto de que la Comisión Europea se encuentra diseñando desde el año 2011 nuevas medidas para aumentar la eficacia de la aplicación de esta Directiva y trabaja sobre su próxima modificación. Los informes de su aplicación de 2013 y 2014 citados sobre su aplicación también plantean la necesidad de salvaguardar y proteger estas garantías. Y la jurisprudencia del TJUE sobre la interpretación de la Directiva pretende reconducirla hacia una línea garantista, si bien con cierta tibieza. 
Es esta, pues, una oportunidad para retomar el citado "valor añadido europeo" en el proceso de retorno de nacionales de terceros Estados en situación irregular para que se manifieste en la protección de los derechos fundamentales procesales. La actualidad, pues, sitúa a la Directiva de Retorno en el punto de mira para reconducir la política migratoria europea hacia un verdadero espacio de seguridad pero también de libertad y, sobre todo, de justicia. En este sentido, la posición del Tribunal de Justicia de la Unión Europea parece decantarse hacia el rechazo de la criminalización de los Derechos estatales penales de las situaciones de retorno cubiertas por la Directiva de Retorno, si bien busca la compatibilidad con los Derechos penales estatales bajo un ejercicio de equilibrismo.

\section{BIBLIOGRAFÍA}

BARREIRO CARRIL, B. (2013). "Informe sobre los centros de internamiento de extranjeros: la normativa española y de la Unión Europea y su aplicación" en AEDIDH, Madrid, 21 enero.

COMUNICACIÓN al Consejo y al Parlamento europeo sobre la política de retorno de la UE (2014) Documento COM (2014) 199 final, Bruselas, 28 de marzo.

DO L 348, de 24.12.2008, p. 98-107. Texto disponible en: http://eurlex.europa.eu/LexUriServ/ LexUriServ.do?uri=OJ:L:2008:348:0098:0107:ES:PDF (Consulta: 12.02.2015).

DOCUMENTO DE LA COMISIÓN EUROPEA COM (2011), 248 final, Bruselas 4.5.11, con el título "Comunicación de la Comisión al Parlamento Europeo, al Consejo, al Comité Económico y social Europeo y al Comité de las regiones. Comunicación sobre migración".

ESPLUGUES MOTA, C. et al. (2011). Nacionalidad y Extranjería. Valencia: Tirant lo Blanch.

GONZÁLEZ SAQUERO, P. (2011). 'La Directiva de 'retorno' y el alcance de la armonización del procedimiento de expulsión de extranjeros" en Papeles de Derecho Europeo e Integración Regional, WP IDEIR, 6: 1-16.

IGLESIAS BUHIGUES, J. L. (2009), "Derechos fundamentales y Derecho Comunitario" en M. P. Calderón Cuadrado et al. El Espacio Europeo de Libertad, Seguridad y Justicia. Avances y Derechos Fundamentales en Materia Procesal. Pamplona: Thomson-Aranzadi, p. 23-38.

IGLESIAS BUHIGUES, J. L. (2006). "Espacio de libertad, de seguridad y de justicia” en Cuadernos de Integración Europea, marzo, $\mathrm{n}^{\circ} 4$.

INFORME AD THE LIMEN: The implementation of the Return Directive in Cyprus, Italy and Spain publicado en diciembre de 2013,

- Andalucía Acoge http://www.acoge.org

- Borderline-europe http://www.borderline-europe.de/

- Borderline Sicilia Onlus http://siciliamigranti.blogspot.it/2011/01/borderlinesiciliaonlus.html

- Kisa Cyprus http://kisa.org.cy/tag/cyprus/

- Mugak-SOS Racismo http://www.mugak.eu/

INFORME DE LA COMISIÓN JURÍDICA DEL CONSEJO GENERAL DE LA ABOGACÍA ESPAÑOLA (2012). "Centros de internamiento en España: régimen vigente y propuestas de futuro", abril, Consejo General de la Abogacía española.

LANCHA MUÑOZ, M. (2014). "La Directiva de retorno a la luz de la jurisprudencia del Tribunal de Justicia de la Unión Europea”, en Revista de Derecho migratorio y extranjería, 34: 211-228.

MINCHEVA, E. (2010). "Case report on Kadzoev, 30 november 2009" en European Journal of Migration and Law, 12: 361-371.

PARDO IRANZO, V. (2009), "El derecho a la interpretación y traducción gratuitas", en M. P. Calderón Cuadrado et al. El Espacio Europeo de Libertad, Seguridad y Justicia. Avances y Derechos Fundamentales en Materia Procesal. Pamplona: Thomson-Aranzadi, pp. 361-391.

PARROT, K. (2011). "Un étranger ne commet pas un délit de seul fait qu'il se trouve en situation irrégulière” en Revue Critique de Droit international privé, pp. 824-846. 
PÉREZ GONZÁLEZ, C. (2012). Migraciones irregulares y Derecho internacional. Valencia: Tirant lo Blanch.

POISSONNIER, G. (2011). “Un étranger en situation irrégulière n’est pas un délinquant” en Reccueil Dalloz, 27 : 1880-1883.

RUBIO CASTRO, A. y MOYA ESCUDERO, M. (2011). "La ciudadanía en Europa y el fenómeno migratorio: nuevas desigualdades y servidumbres voluntarias" en Anales de la Cátedra Francisco Suárez, 45: 183-227.

SORROZA BLANCO, A. (2008). "Crónica de una controversia anunciada: la Directiva europea de retorno de inmigrantes en situación ilegal” en Revista de Estudios Jurídicos, 8: 1-10.

\section{Breve currículo:}

\section{Isabel Reig Fabado}

Profesora de Derecho internacional privado de la Universitat de València. Ha participado en más de quince proyectos de investigación y ha sido investigadora principal en dos de ellos en materia migratoria. Actualmente, dirige un Módulo Jean Monnet sobre Política migratoria europea y ciudadanía de la Unión Europea. Ha organizado varios Seminarios sobre extranjería desde el año 2013 y en el año 2014 ha dirigido la publicación de un libro colectivo sobre los derechos fundamentales de los extranjeros en España. Imparte docencia en grado y posgrado en materias de Derecho internacional privado, comercio internacional y Extranjería. 